\title{
Frequency of cataract surgery and its impact on visual function-results from the German Gutenberg Health Study
}

\author{
Alexander K. Schuster ${ }^{1}$ - S. Nickels ${ }^{1}$ - N. Pfeiffer ${ }^{1}$ - I. Schmidtmann ${ }^{2}$ • P. S. Wild ${ }^{3,4,5} \cdot$ T. Münzel $^{6} \cdot$ M. E. Beutel $^{7}$. \\ K. J. Lackner ${ }^{8}$ • U. Vossmerbaeumer ${ }^{1}$
}

Received: 2 February 2020 / Revised: 21 April 2020 / Accepted: 25 May 2020 / Published online: 8 June 2020

(C) The Author(s) 2020

\begin{abstract}
Purpose To determine the frequency of cataract surgery in Germany and to evaluate its impact on visual function in an adult population.

Methods The population-based Gutenberg Health Study was conducted in Germany with its baseline examination between 2007 and 2012 and a 5-year follow-up examiantion. An ophthalmological examination including slit-lamp examination, ocular biometry, and Scheimpflug imaging was carried out. Overall and age-specific frequencies of unilateral and bilateral cataract surgery within 5 years were computed including the $95 \%$ confidential intervals [95\%-CI]. Association analyses were conducted to determine social and ocular associated factors using multivariable logistic regression analysis. Vision-related quality of life was assessed using NEI VFQ-25.

Results A total of 10,544 people aged 35 to 74 years were bilateral phakic at baseline and had information on lens status at the 5 year examination. Of these, 168 had unilateral cataract surgery (1.6\% [1.4-1.9\%]), and 448 had bilateral cataract surgery (4.2\% [3.9-4.7\%]) in the following 5 years. The frequency of cataract surgery increased with age: $45-54$-year-old subjects had twice as often cataract surgery (in at least on eye: $\mathrm{OR}=2.32$ ) than at age $35-44$ years. The frequency further strongly increases with age $(55-64$ years: $\mathrm{OR}=10.5 ; 65-74$ years: $\mathrm{OR}=43.8, p<0.001)$. Subjects with glaucoma were more likely to have cataract surgery $(\mathrm{OR}=2.52, p<0.001)$. Visual function increased when undergoing bilateral cataract surgery.

Conclusions The frequency of cataract surgery is low at younger ages and increases up to $26 \%$ at age $70-74$ years. Persons with glaucoma are more likely to undergo cataract surgery at population-based level in Germany.
\end{abstract}

Keywords Epidemiology · Cataract surgery · Pseudophakia · Visual acuity · Quality of life

Schuster AK and Nickels S contributed equally and share first authorship

Electronic supplementary material The online version of this article (https://doi.org/10.1007/s00417-020-04770-0) contains supplementary material, which is available to authorized users.

Alexander K. Schuster

alexander.schuster@uni-mainz.de

1 Department of Ophthalmology, University Medical Center of the Johannes Gutenberg-University Mainz, Langenbeckstr. 1, Mainz 55131, Germany

2 Institute of Biomedical Statistics, Epidemiology and Informatics, University Medical Center of the Johannes Gutenberg-University Mainz, Mainz, Germany

3 Preventive Cardiology and Preventive Medicine, Center for Cardiology, University Medical Center of the Johannes Gutenberg-University Mainz, Mainz, Germany
4 Center for Thrombosis and Hemostasis, University Medical Center of the Johannes Gutenberg-University Mainz, Mainz, Germany

5 DZHK (German Center for Cardiovascular Research), partner site Rhine-Main, Mainz, Germany

6 Center for Cardiology, Cardiology I, University Medical Center Mainz, Mainz, Germany

7 Department of Psychosomatic Medicine and Psychotherapy, University Medical Center Mainz, Mainz, Germany

8 Institute of Clinical Chemistry and Laboratory Medicine, University Medical Center Mainz, Mainz, Germany 


\section{Introduction}

Cataract is the leading cause of visual impairment and blindness worldwide, especially in developing countries [1]. In the western countries, cataract surgery including phacoemulsification and implantation of an artificial intraocular lens is the most common procedure to remove the clouded lens and to restore vision loss due to cataract.

While the frequency and outcome of cataract surgery in developing countries is well documented [2-10], the frequency of cataract surgery in industrialized countries and its impact on daily life activities is less investigated [11-14]. Several technological improvements in the last two decades have improved cataract surgery resulting in a relatively safe and common procedure. As part of refractive surgery, even clear lens extractions are nowadays performed [15].

We recently described the prevalence of pseudophakia and aphakia and its impact on vision-related quality of life in the German population [16]. Now, we move forward and analyze the frequency of cataract surgery within 5 years and describe factors leading to higher frequency of cataract surgery. In addition, the impact of cataract surgery on vision-related quality of life is evaluated.

\section{Materials and methods}

The Gutenberg Health Study (GHS) is a prospective, population-based, observational cohort study conducted in the Rhine-Main region in Germany. The sample of 15,010 participants was randomly drawn from local governmental registry offices. The study cohort was equally stratified by sex within each decade of age. More details regarding the study design are described in Höhn et al. [17]. In brief, the baseline examination of the study cohort was carried out between 2007 and 2012 and the 5-year follow-up between 2012 and 2017. The study protocol and study documents were approved by the local ethics committee of the Medical Chamber of Rhineland-Palatinate, Germany (reference no. 837.020.07; original vote: 22.3.2007, latest update: 20.10.2015). According to the tenets of the Declaration of Helsinki, written informed consent was obtained from all participants prior to entering them in the study.

For each participant, a comprehensive ophthalmological examination was conducted, including objective refraction (Humphrey Automated Refractor/Keratometer (HARK) 599, Carl Zeiss Meditec AG, Jena, Germany) and distancecorrected visual acuity, non-contact tonometry (Nidek NT2000, Nidek Co, Japan) at baseline and follow-up. Slit-lamp examination of the anterior segment and funduscopy was performed at baseline. Ophthalmic conditions (e.g., phakia, pseudophakia and aphakia) were documented using standardized documentation sheets. These variables (aphakia, pseudophakia) were validated using refraction and the ophthalmic medical history. Eye diseases were recorded as selfreport for glaucoma, age-related macular degeneration, and corneal disease.

At 5-year follow-up, Scheimpflug imaging, ocular biometry, and fundus photography was conducted. In all eyes with a lens thickness $\leq 2 \mathrm{~mm}$ or missing value, Scheimpflug images were evaluated by two trained graders (AKS, PW) for the presence of a crystalline lens (examples are given in supplemental figure 1). In case of deviation (kappa $=0.99$ for inter-rater reliability), an experienced cataract and refractive surgeon $(\mathrm{UVb})$ took the decision. In addition, a masked sample of eyes with lens thickness $>2 \mathrm{~mm}$ was included.

Vision-related quality of life was assessed using the German version of the National Eye Institute 25-Item Visual Function Questionnaire (NEI VFQ-25) [18, 19]. The questionnaire was self-administered as print-out and Rasch-based analysis was computed to result in measures for visual function scale (VFS) and socio-emotional scale (SES), as described before [20, 21].

Diabetes was diagnosed in those individuals with $\mathrm{HbA} 1 \mathrm{c}$ $\geq 6.5 \%$, taking diabetic medication or having been diagnosed by a physician.

Socioeconomic status was defined according to the index used for the German Health Update 2009 (GEDA) and ranged from 3 to 21 [22]. The type of health insurance (private vs. statutory) was questioned.

\section{Study population}

All subjects with bilateral phakia at baseline examination were included for data analysis. Individuals with unilateral phakia were included in a separate analysis sample.

\section{Data and statistical analysis}

All variables were first tested for normal distribution. Medians, interquartile ranges, minimums, and maximums were calculated for all primary and secondary variables. For variables that were normally distributed, means and standard deviations were computed as well.

The primary outcome was lens status at 5-year follow-up examination. Secondary outcome was monocular distantcorrected visual acuity, and vision-related quality of life as visual functioning scale and socio-emotional scale.

First, age-specific frequency of cataract surgery was calculated including 95\% confidence intervals. Associated parameters were evaluated using multivariable logistic regression models. Models were conducted to compare (1) people with unilateral cataract surgery to those without cataract surgery, (2) people with bilateral cataract surgery to those without cataract surgery, and (3) people with any cataract surgery. The included covariates were age (in decades), 
sex, socioeconomic status, diabetes, type of health insurance, self-reported age-related macular degeneration, glaucoma, and corneal disease. These variables were chosen, as aging and diabetes are well-known risk factor for cataract, while the influence of social factors such as socioeconomic status, sex, and type of health insurance on cataract surgery might differ between countries. The different eye diseases were included to investigate whether glaucoma was related to a higher frequency of cataract surgery in a populationbased study setup, while self-report of age-related macular degeneration and corneal disease was supposed to not have any effect, although these subjects may more frequently consult an ophthalmologist.

An intra-individual comparison (baseline to follow-up examination) was performed to evaluate differences in refraction (sphere, astigmatism), visual acuity, and vision-related quality of life.

Self-reported cataract surgery within the last 5 years at follow-up was compared to objective measure of cataract surgery and kappa-statistics were computed.

This study was performed as an explorative study to analyze the frequency of cataract surgery and the factors associated with this condition. All $p$ values should be regarded as continuous parameters that reflect the level of evidence and are therefore reported exactly. The data were processed using statistical analysis software (R version 3.5.2 [2018-12-20]).

\section{Results}

A total of 13,993 study subjects had bilateral phakia at baseline examination, and thereof, 11,669 (83.4\%) re-attended the 5 -year follow-up examination. Of them, bilateral lens status data were missing in 1125 people (9.6\%) at 5-year follow-up leading to 10,544 subjects included in this analysis. Item-nonresponder analysis showed that participants with missing information were older, had a lower socioeconomic status, and had more systemic comorbidities (supplemental table 1), while they were similar in eye parameters. In a second analysis sample, those with one eye phakic and the fellow eye pseudophakic at baseline examination and lens status measurement at 5-year follow-up examination were included $(n=139)$ (Table 1).

Four hundred forty-eight of 10,544 people $(4.2 \%$; $95 \%$ confidence interval [3.9-4.7\%]) underwent bilateral cataract surgery, while 168 (1.6\% [1.4-1.9\%]) had unilateral cataract surgery. For both, an increase with age was observed (Fig. 1). While at age 35-39 years only $0.28 \%$ had cataract surgery in the following 5 years in at least one eye, this frequency increased up to $26.0 \%$ at age 70 74 years.

The agreement between self-reported cataract surgery during the recent 5 years and an observed change in the lens status was $99.2 \%$ (Cohen's Kappa $=0.93$, when analyzing the change in at least one eye.

Logistic regression analyses showed that age, diabetes, and glaucoma were independently associated with undergoing cataract surgery in the next 5 years (Table 2). Neither sex, nor socioeconomic status, health insurance status, and corneal disease did have an impact on cataract surgery in the following 5 years in one or both eyes.

Distance-corrected visual acuity decreased by 0.10 logMAR (median) over 5 years in eyes not undergoing cataract surgery to $0.10 \operatorname{logMAR}$ in right eyes and 0.10 in left eyes. Eyes that underwent bilateral cataract surgery had baseline $\log$ MAR of 0.22 in both eyes, and 0.22 in right eyes and 0.10 in left eyes at 5 -year follow-up after cataract surgery (Fig. 2a). In participants with unilateral surgery, the visual acuity of the treated eye increased from 0.22 to 0.10 , while the untreated eye decreased from 0.10 to 0.22 (Fig. 2b).

For those with one eye phakic and the other pseudophakic status $(n=139)$ at baseline, $44.6 \%$ [36.3-53.3\%] had cataract surgery in the fellow eye within the following 5 years. Visual acuity remained stable in fellow pseudophakic eyes over time, while decreased in eyes without cataract surgery and increased in eyes with cataract surgery over time (supplemental figure 2).

The change in vision-related quality of life in terms of the visual functioning scale score (VFS) of NEI VFQ-25 is similar between participants with no cataract surgery $(n=9928)$ and those with unilateral cataract surgery $(n=$ 168). In participants with bilateral cataract surgery $(n=$ 448), the median VFS is 5.4 [IQR - 2.8; 13.7] points higher at follow-up than at baseline (Fig. 3). The median socio-emotional scale score decreased in all participants, but the decrease is highest in participants with unilateral cataract surgery and lowest in participants with bilateral cataract surgery (Fig. 3).

\section{Discussion}

For the first time, we report the frequency of cataract surgery in Germany in a population-based study. We found that $4.2 \%$ of the 35 - to 74 -year-old population has bilateral cataract surgery and $1.6 \%$ unilateral cataract surgery during an observation interval of 5 years. These people are more likely to be older and to suffer from diabetes. Sex or health insurance status is not associated with cataract surgery in Germany.

There is growing evidence that the prevalence of cataract and its management is linked to socioeconomic factors [23]. Prevalence of age-related cataract is related to lower socioeconomic status in the USA [24] and India [25]. In the Singapore Malay Eye Study, a relationship between 
Table 1 Baseline characteristics of the analysis sample. Study participants from the Gutenberg Health Study with bilateral/ unilateral phakia at baseline (2007-2012) and lens status at 5year follow-examination (20122017)

\begin{tabular}{lll}
\hline Baseline data & Bilateral phakia at baseline & Unilateral phakia at baseline \\
\hline Number (n) & 10,544 & 139 \\
Sex (women) & $5129(48.6 \%)$ & $64(46.0 \%)$ \\
Age (years) & $53.84 \pm 10.67$ & $64.73 \pm 7.62$ \\
Socioeconomic status & $13.3 \pm 4.4$ & $13.1 \pm 4.9$ \\
Body mass index (kg/m $\left.{ }^{2}\right)$ & $27.1 \pm 4.8$ & $27.7 \pm 4.3$ \\
Diabetes (yes) & $754(7.2 \%)$ & $22(15.8 \%)$ \\
Arterial hypertension (yes) & $4927(46.7 \%)$ & $87(62.6 \%)$ \\
Type of health insurance & & $2(2.0 \%)$ \\
Private (yes, otherwise statutory) & $271(3.3 \%)$ & \\
Ophthalmic parameters & & $0.22[0.00,0.22]^{\mathrm{a}}$ \\
Visual acuity OD (median [IQR]) & $0.00[0.00,0.10]$ & $0.22[0.00,0.30]$ \\
Visual acuity OS (median [IQR]) & $0.00[0.00,0.10]$ & $-0.86 \pm 2.61^{\mathrm{b}}$ \\
Spherical equivalent (diopter) OD & $-0.47 \pm 2.51$ & $-0.65 \pm 2.43$ \\
Spherical equivalent (diopter) OS & $-0.46 \pm 2.52$ & $14.26 \pm 3.12^{\mathrm{c}}$ \\
Intraocular pressure (mmHg) OD & $14.10 \pm 2.81$ & $14.18 \pm 2.79$ \\
Intraocular pressure (mmHg) OS & $14.25 \pm 2.86$ & $13(9.4 \%)$ \\
Eye diseases (self-reported) & & $3(2.2 \%)$ \\
Glaucoma & $179(1.7 \%)$ & $4(2.9 \%)$ \\
Diabetic retinopathy & $31(0.3 \%)$ & $7(5.0 \%)$ \\
Age-related macular degeneration & $31(0.3 \%)$ & \\
Corneal disease & $183(1.7 \%)$ & \\
\hline
\end{tabular}

${ }^{\text {a }}$ With respect to phakic/pseudophakic eyes: $0.18 \pm 0.20 / 0.25 \pm 0.39$

${ }^{\mathrm{b}}$ With respect to phakic/pseudophakic eyes: $-0.90 \pm 3.35 /-0.68 \pm 2.12$

${ }^{\mathrm{c}}$ With respect to phakic/pseudophakic eyes: $14.22 \pm 2.98 / 13.85 \pm 3.04$ indicators of socioeconomic status, namely education level and income, was associated with nuclear sclerotic cataract prevalence [26].

Cataract surgery is reported to be a highly cost-effective treatment for a preventable cause of visual impairment in first and second eyes [27, 28]. Nevertheless, barriers to cataract surgery have been identified, not only in developing countries but also in the USA [29-32]. In the Los Angeles Latino Eye Study, low socioeconomic status was associated with an unmet need for visually significant cataract surgery [29]. We therefore investigated whether socioeconomic status was associated with cataract surgery in Germany as well. Our data showed that undergoing cataract surgery was independent of socioeconomic status, which is not surprising in a country having an obligate health insurance system and covering almost the total population. Costs of cataract surgery with monofocal intraocular lens implantation are reimbursed in both the private and statutory healthcare system. Nevertheless, there are additional private costs for patients undergoing cataract surgery such as measuring the dimensions of the eye with optical biometry for IOL power calculation or when receiving a customized IOL. Unfortunately, our data did not allow to further investigate these aspects.
Cataract surgery is part of the treatment cascade in both open-angle and angle-closure glaucoma. Seol et al. reported reduction in intraocular pressure and less intraocular pressure spikes in normal subjects and normal-tension glaucoma [33]. In primary angle-closure glaucoma, Azuara-Blanco et al. showed that early lens extraction has greater efficacy and is more cost-effective than peripheral laser iridotomy [34]. This was also found in our data: subjects suffering from glaucoma at baseline were more likely to undergo cataract surgery within the following 5 years.

Diabetes and impaired fasting glucose level is a known risk factor for cataract incidence in several population-based studies [35-37]. In Germany, there is a national guideline on diabetic retinopathy screening that incorporates a slit-lamp examination of the eye at least every 1-2 years [38]. Consequently, opacification of the lens will be observed and necessary treatment will be initiated. This association was also present in our analysis: persons suffering from diabetes showed a 1.4-fold higher frequency of cataract surgery independently from aging. Our risk estimates for undergoing cataract surgery were slightly lower than those from a previous multi-ethnic Asian population from Singapore [39], which might be due to differences in diabetic treatment regime and in blood sugar control between the two countries. 
Fig. 1 Age-specific frequencies and $95 \%$ confidential intervals for cataract surgery within the last 5 years. Data from the populationbased German Gutenberg Health Study (2007-2017) analyzing study participants being bilateral phakic at baseline examination. a bilateral cataract surgery. b unilateral cataract surgery
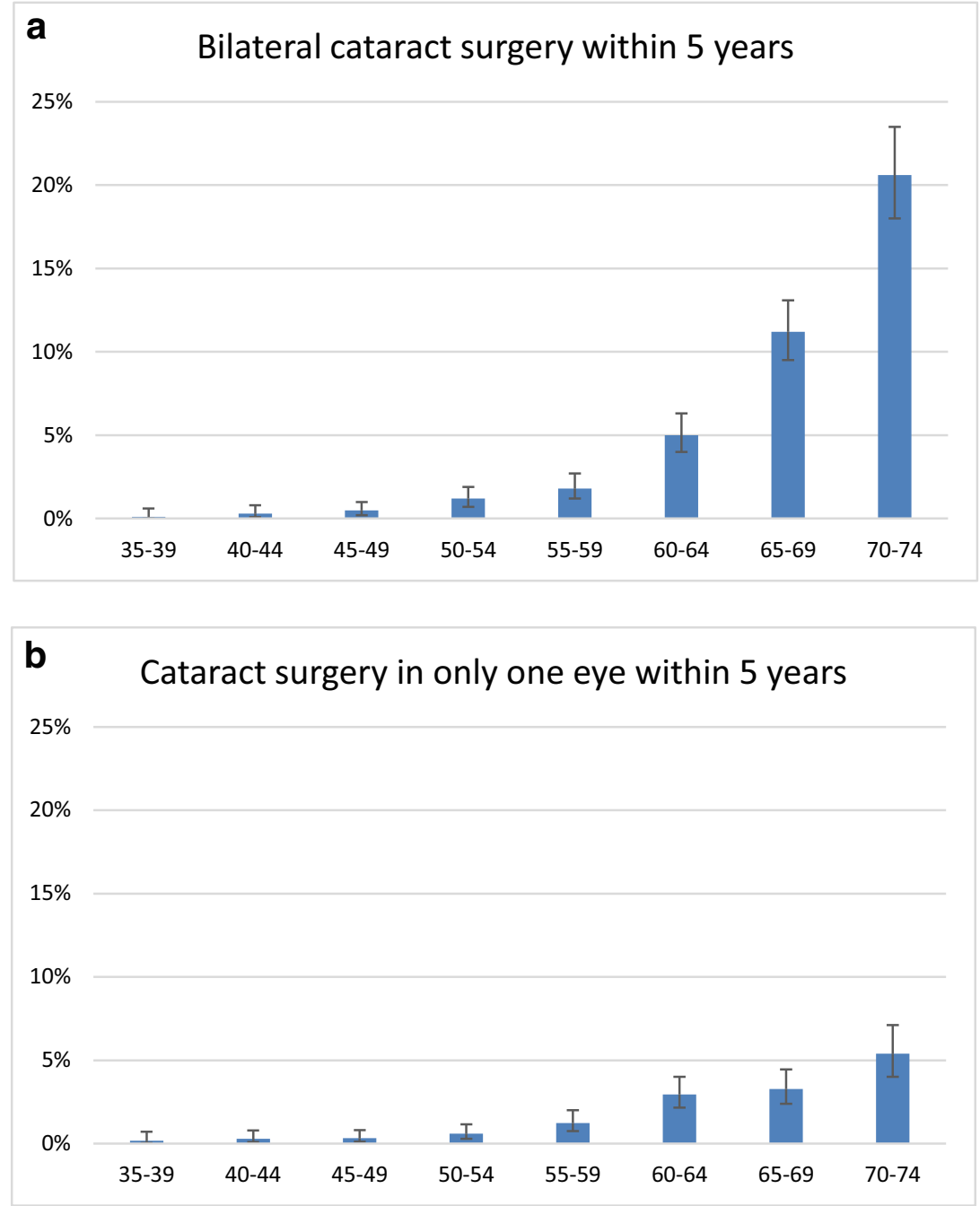

Table 2 Association analysis of factors leading to cataract surgery within 5 years. Data from the German Gutenberg Health Study (2007-17) including bilateral phakic subjects at baseline. Multivariable logistic regression analysis was computed

\begin{tabular}{|c|c|c|c|c|c|c|}
\hline & \multicolumn{2}{|c|}{ Unilateral cataract surgery } & \multicolumn{2}{|c|}{ Bilateral cataract surgery } & \multicolumn{2}{|c|}{ Any cataract surgery } \\
\hline & OR $(95 \% \mathrm{CI})$ & $p$ & OR $(95 \% \mathrm{CI})$ & $p$ & OR $(95 \% \mathrm{CI})$ & $p$ \\
\hline Age: & & $<0.001$ & & $<0.001$ & & $<0.001$ \\
\hline 35-44 years & Reference & & Reference & & Reference & \\
\hline $45-54$ years & $1.54(0.57 ; 4.18)$ & & $3.48(1.17 ; 10.37)$ & & $2.32(1.12 ; 4.78)$ & \\
\hline 55-64 years & $6.93(2.93 ; 16.4)$ & & $15.7(5.73 ; 43.2)$ & & $10.5(5.50 ; 20.2)$ & \\
\hline $65-74$ years & $14.2(6.08 ; 33.3)$ & & $79.5(29.4 ; 216)$ & & $43.8(23.2 ; 83.0)$ & \\
\hline Sex (female) & $1.09(0.76 ; 1.57)$ & 0.64 & $1.09(0.87 ; 1.38)$ & 0.44 & $1.11(0.90 ; 1.35)$ & 0.33 \\
\hline Socioeconomic status & $1.02(0.97 ; 1.06)$ & 0.49 & $0.98(0.95 ; 1.01)$ & 0.18 & $0.99(0.97 ; 1.02)$ & 0.45 \\
\hline Diabetes (yes) & $1.06(0.62 ; 1.83)$ & 0.82 & $1.44(1.06 ; 1.96)$ & 0.019 & $1.36(1.03 ; 1.79)$ & 0.031 \\
\hline Health insurance (private) & $0.80(0.25 ; 2.57)$ & 0.70 & $1.40(0.74 ; 2.64)$ & 0.31 & $1.22(0.69 ; 2.15)$ & 0.50 \\
\hline Glaucoma (yes) & $1.72(0.74 ; 4.02)$ & 0.24 & $2.56(1.59 ; 4.14)$ & $<0.001$ & $2.52(1.62 ; 3.93)$ & $<0.001$ \\
\hline AMD (yes) & - & - & $2.79(1.04 ; 7.49)$ & 0.059 & $2.04(0.76 ; 5.45)$ & 0.18 \\
\hline Corneal disease (yes) & $0.61(0.15 ; 2.51)$ & 0.46 & $1.06(0.55 ; 2.05)$ & 0.87 & $0.94(0.69 ; 2.15)$ & 0.84 \\
\hline
\end{tabular}


Fig. 2 Distant-corrected visual acuity decreases in subjects without cataract surgery over 5 years, while increases in those with bilateral cataract surgery. Data at baseline and 5-year follow-up examination in eyes of participants with a both eyes without cataract surgery at baseline and bilateral cataract surgery during 5-year follow-up interval and $\mathbf{b}$ both eyes without cataract surgery at baseline and unilateral cataract surgery during 5 -year follow-up interval. Data from the population-based German Gutenberg Health Study (2007-2017) are presented in box-plots (gray boxes: interquartile range (IQR); black line: median). OD: right eyes; OS: left eyes
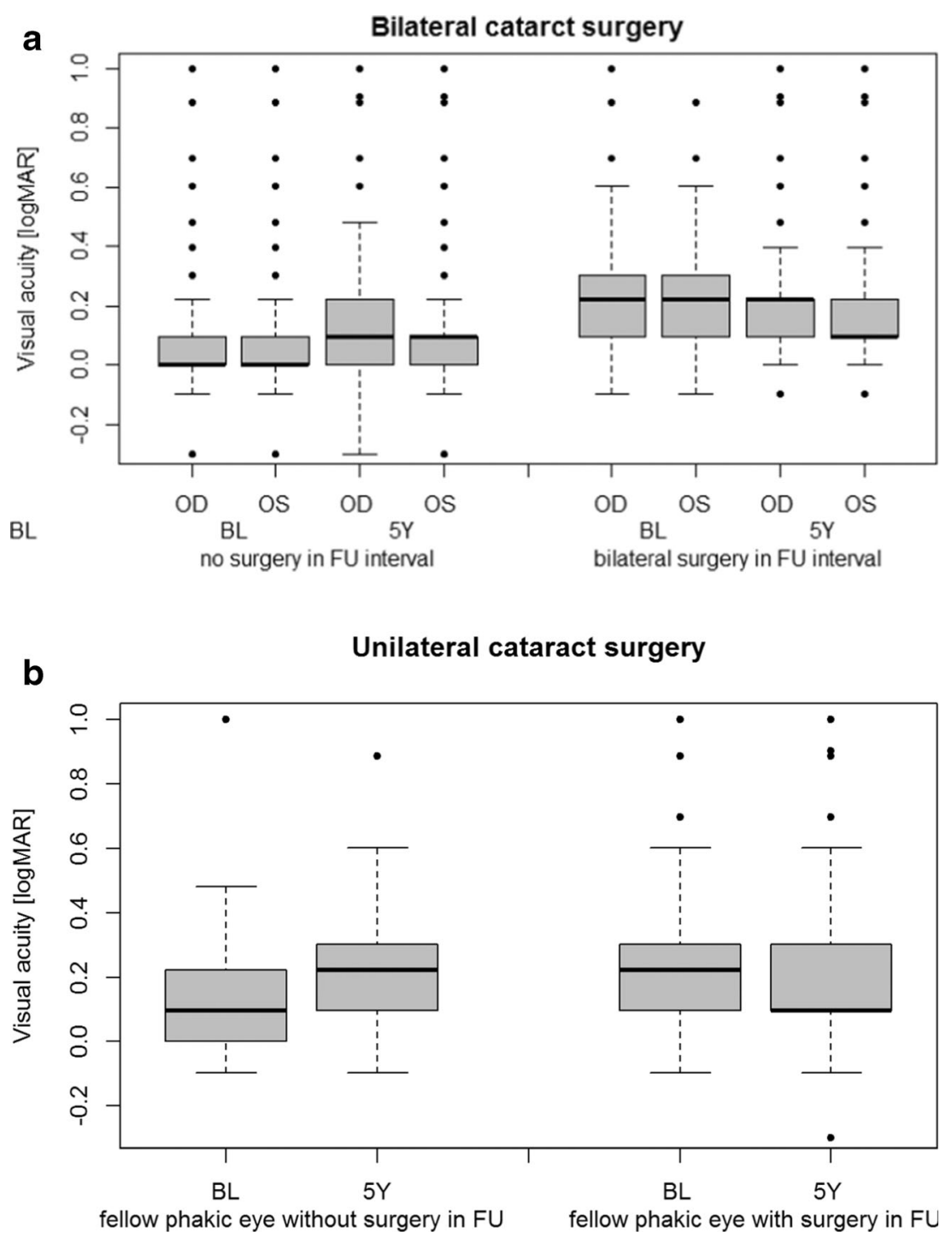

In terms of vision-related quality of life, participants who received bilateral cataract surgery benefited the most. This is in line with previous results from the GHS, where we found similar VRQoL in bilateral phakic and pseudophakic subjects, but 6-point lower VRQoL in monolateral pseudophakic [16]. For cataract surgery, multiple studies reported an increase of VRQoL in subjects after cataract surgery of the second eye [40-42]. This is in line with the growing body of evidence that both eyes have a considerable impact on VRQoL, and not only the better-seeing eye [43-45].

There are methodological limitations of this study: first, the lens status was determined by slit-lamp examination at baseline using a neutral pupil. At follow-up examination, lens status was evaluated with LenStar measures and analyzing Scheimpflug images, showing high reliability measures. This might have an impact on our estimates; nevertheless, both methods are held as valid methods for determination of lens status. As our study was solely conducted in Germany, the healthcare system may have an influence on the supply with cataract surgery and cannot be directly generalized to other countries. In addition, our study population was 35 to 74 years old at baseline; therefore, frequencies of cataract surgery within the next 5 years are only valid for this age range. In a population-based study, response to study invitation might be a limitation. In our study, the initial response was $55.5 \%$ (effective recruitment efficacy proportion) and the response for the 5 -year follow-up examination was $83.4 \%$ for the analyzed study sample. As there is no information about eye health in non-responders, we are not able to determine whether people with eye diseases might have less likely participated. Regarding differences in response at follow-up examination, male subjects at younger age and female subjects at older age were less likely to take part. 
Fig. 3 Vision-related Quality of Life increases in the visual functioning scale (a) after bilateral cataract surgery, but not in the socio-emotional scale (b). Data from the population-based German Gutenberg Health Study (2007-2017) at baseline (BL) and 5-year follow-up interval (FU), based on Rasch-transformed NEI VFQ-25 measurements, are presented in box-plots (gray boxes: interquartile range (IQR); black line: median)
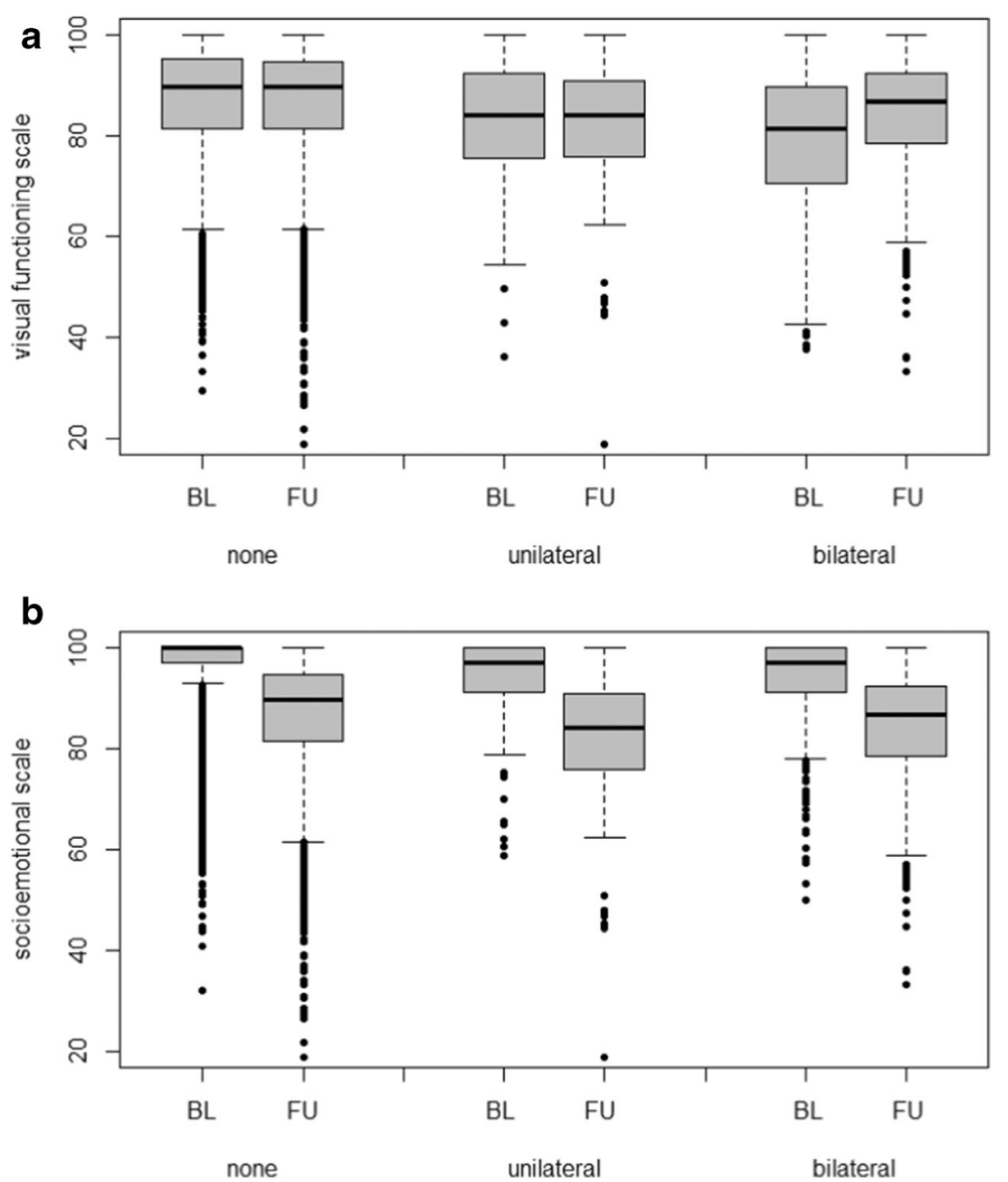

In summary, the frequency of cataract surgery is low at younger ages and increases up to $26 \%$ at age $70-74$ years. Persons with glaucoma are more likely to undergo cataract surgery at population-based level in Germany, as are those suffering from diabetes.

Acknowledgments We would like to thank Paul Witte (PW) for his help when carrying out the grading of Scheimpflug images. We thank all study participants for their willingness to provide data for this research project, and we are indebted to all coworkers for their enthusiastic commitment.

Funding information Open Access funding provided by Projekt DEAL. The Gutenberg Health Study is funded through the government of Rhineland-Palatinate (Stiftung Rheinland-Pfalz für Innovation, contract AZ 961-386261/733), the research programs "Wissen schafft Zukunft" and "Center for Translational Vascular Biology (CTVB)" of the Johannes Gutenberg-University of Mainz, and its contract with Boehringer Ingelheim and PHILIPS Medical Systems, including an unrestricted grant for the Gutenberg Health Study. Philipp S. Wild is funded by the Federal Ministry of Education and Research (BMBF 01EO1503) and he is PI of the German Center for Cardiovascular Research (DZHK).
Schuster AK holds the professorship for ophthalmic healthcare research endowed by Stiftung Auge and financed by Deutsche Ophthalmologische Gesellschaft and Berufsverband der Augenärzte Deutschlands e.V. He received research funding from Allergan, Bayer Vital, Novartis and Heidelberg Engineering.

Nickels S received reimbursement of travel expenses from Heidelberg Engineering.

\section{Compliance with ethical standards}

Conflict of interest The authors declare that they have no conflict of interest.

Informed consent The study protocol and study documents were approved by the local ethics committee of the Medical Chamber of Rhineland-Palatinate, Germany (reference no. 837.020.07; original vote: 22.3.2007, latest update: 20.10.2015). According to the tenets of the Declaration of Helsinki, written informed consent was obtained from all participants prior to entering the study.

Open Access This article is licensed under a Creative Commons Attribution 4.0 International License, which permits use, sharing, adaptation, distribution and reproduction in any medium or format, as 
long as you give appropriate credit to the original author(s) and the source, provide a link to the Creative Commons licence, and indicate if changes were made. The images or other third party material in this article are included in the article's Creative Commons licence, unless indicated otherwise in a credit line to the material. If material is not included in the article's Creative Commons licence and your intended use is not permitted by statutory regulation or exceeds the permitted use, you will need to obtain permission directly from the copyright holder. To view a copy of this licence, visit http://creativecommons.org/licenses/by/4.0/.

\section{References}

1. Congdon NG, Friedman DS, Lietman T (2003) Important causes of visual impairment in the world today. Jama 290:2057-2060. https:// doi.org/10.1001/jama.290.15.2057

2. Bourne RR, Dineen BP, Ali SM, Huq DM, Johnson GJ (2003) Outcomes of cataract surgery in Bangladesh: results from a population based nationwide survey. Br J Ophthalmol 87:813-819

3. Dandona L, Dandona R, Naduvilath TJ, McCarty CA, Mandal P, Srinivas M, Nanda A, Rao GN (1999) Population-based assessment of the outcome of cataract surgery in an urban population in southern India. Am J Ophthalmol 127:650-658

4. Lavanya R, Wong TY, Aung T, Tan DT, Saw SM, Tay WT, Wang JJ (2009) Prevalence of cataract surgery and post-surgical visual outcomes in an urban Asian population: the Singapore Malay Eye Study. Br J Ophthalmol 93:299-304. https://doi.org/10.1136/bjo. 2008.148650

5. Liu B, Xu L, Wang YX, Jonas JB (2009) Prevalence of cataract surgery and postoperative visual outcome in Greater Beijing: the Beijing Eye Study. Ophthalmology 116:1322-1331. https://doi. org/10.1016/j.ophtha.2009.01.030

6. Murthy GV, Gupta S, Ellwein LB, Munoz SR, Bachani D, Dada VK (2001) A population-based eye survey of older adults in a rural district of Rajasthan: I. Central vision impairment, blindness, and cataract surgery. Ophthalmology 108:679-685

7. Nangia V, Jonas JB, Gupta R, Khare A, Sinha A (2011) Prevalence of cataract surgery and postoperative visual outcome in rural central India Central India Eye and Medical Study. J Cataract Refract Surg 37:1932-1938. https://doi.org/10.1016/j.jcrs.2011.08.020

8. Salomao SR, Soares FS, Berezovsky A, Araujo-Filho A, Mitsuhiro MR, Watanabe SE, Carvalho AV, Pokharel GP, Belfort R Jr, Ellwein LB (2009) Prevalence and outcomes of cataract surgery in Brazil: the Sao Paulo Eye Study. Am J Ophthalmol 148:199206.e192. https://doi.org/10.1016/j.ajo.2009.02.019

9. Vashist P, Talwar B, Gogoi M, Maraini G, Camparini M, Ravindran RD, Murthy GV, Fitzpatrick KE, John N, Chakravarthy U, Ravilla TD, Fletcher AE (2011) Prevalence of cataract in an older population in India: the India study of agerelated eye disease. Ophthalmology 118: 272-278.e271-272 doi: https://doi.org/10.1016/j.ophtha.2010.05.020

10. Zhao J, Ellwein LB, Cui H, Ge J, Guan H, Lv J, Ma X, Yin J, Yin ZQ, Yuan Y, Liu H (2010) Prevalence and outcomes of cataract surgery in rural China the China nine-province survey. Ophthalmology 117:2120-2128. https://doi.org/10.1016/j.ophtha. 2010.03.005

11. Baranano AE, Wu J, Mazhar K, Azen SP, Varma R (2008) Visual acuity outcomes after cataract extraction in adult latinos. The Los Angeles Latino Eye Study. Ophthalmology 115:815-821. https:// doi.org/10.1016/j.ophtha.2007.05.052

12. Congdon N, Vingerling JR, Klein BE, West S, Friedman DS, Kempen J, O'Colmain B, Wu SY, Taylor HR (2004) Prevalence of cataract and pseudophakia/aphakia among adults in the United
States. Arch Ophthalmol 122:487-494. https://doi.org/10.1001/ archopht.122.4.487

13. Daien V, Le Pape A, Heve D, Carriere I, Villain M (2015) Incidence and characteristics of cataract surgery in France from 2009 to 2012: a national population study. Ophthalmology 122: 1633-1638. https://doi.org/10.1016/j.ophtha.2015.04.017

14. Scott NW, Azuara-Blanco A, Solborg Bjerrum S, Mikkelsen KL, la Cour M (2015) Epidemiology of 411140 cataract operations performed in public hospitals and private hospitals/clinics in Denmark between 2004 and 2012. Eye (Lond) 93:16-23. https://doi.org/10. 1111/aos. 12576

15. Fernandez-Vega L, Alfonso JF, Villacampa T (2003) Clear lens extraction for the correction of high myopia. Ophthalmology 110: 2349-2354. https://doi.org/10.1016/s0161-6420(03)00794-2

16. Schuster AK, Pfeiffer N, Schulz A, Nickels S, Hohn R, Wild PS, Blettner M, Munzel T, Beutel ME, Lackner KJ, Vossmerbaeumer U (2017) The impact of pseudophakia on vision-related quality of life in the general population - the Gutenberg Health Study. Aging (Albany NY) 9:1030-1040. https://doi.org/10.18632/aging.101208

17. Hohn R, Kottler U, Peto T, Blettner M, Munzel T, Blankenberg S, Lackner KJ, Beutel M, Wild PS, Pfeiffer N (2015) The ophthalmic branch of the Gutenberg Health Study: study design, cohort profile and self-reported diseases. PLoS One 10:e0120476. https://doi.org/ 10.1371/journal.pone.0120476

18. Mangione CM, Lee PP, Gutierrez PR, Spritzer K, Berry S, Hays RD (2001) Development of the 25-item National Eye Institute Visual Function Questionnaire. Arch Ophthalmol 119:1050-1058

19. Franke GH, Esser J, Voigtländer A, Mähner N (1998) Der National Eye Institute Visual Function Questionnaire (NEI-VFQ)-Erste Ergebnisse zur psychometrischen Überprüfung eines Verfahrens zur Erfassung der Lebensqualität bei Sehbeeinträchtigten. Z Med Psychol 7:178-184

20. Nickels S, Schuster AK, Singer S, Wild PS, Laubert-Reh D, Schulz A, Finger RP, Michal M, Beutel ME, Munzel T, Lackner KJ, Pfeiffer N (2017) The National Eye Institute 25-Item Visual Function Questionnaire (NEI VFQ-25) - reference data from the German population-based Gutenberg Health Study (GHS). Health Qual Life Outcomes 15:156. https://doi.org/10.1186/s12955-0170732-7

21. Pesudovs K, Gothwal VK, Wright T, Lamoureux EL (2010) Remediating serious flaws in the National Eye Institute Visual Function Questionnaire. J Cataract Refract Surg 36:718-732. https://doi.org/10.1016/j.jcrs.2009.11.019

22. Lampert T, Kroll LE, Muters S, Stolzenberg H (2013) Measurement of the socioeconomic status within the German Health Update 2009 (GEDA). Bundesgesundheitsbl Gesundheitsforsch Gesundheitsschutz 56:131-143. https://doi. org/10.1007/s00103-012-1583-3

23. Mundy KM, Nichols E, Lindsey J (2016) Socioeconomic disparities in cataract prevalence, characteristics, and management. Semin Ophthalmol 31:358-363. https://doi.org/10.3109/08820538.2016. 1154178

24. Tielsch JM, Sommer A, Katz J, Quigley H, Ezrine S (1991) Socioeconomic status and visual impairment among urban Americans. Baltimore Eye Survey Research Group. Arch Ophthalmol 109:637-641. https://doi.org/10.1001/archopht.1991. 01080050051027

25. Singh S, Pardhan S, Kulothungan V, Swaminathan G, Ravichandran JS, Ganesan S, Sharma T, Raman R (2019) The prevalence and risk factors for cataract in rural and urban India. Indian J Ophthalmol 67:477-483. https://doi.org/10.4103/ijo.IJO 112717

26. Wu R, Wang JJ, Mitchell P, Lamoureux EL, Zheng Y, Rochtchina E, Tan AG, Wong TY (2010) Smoking, socioeconomic factors, and age-related cataract: the Singapore Malay Eye Study. Arch 
Ophthalmol 128:1029-1035. https://doi.org/10.1001/ archophthalmol.2010.147

27. Busbee BG, Brown MM, Brown GC, Sharma S (2002) Incremental cost-effectiveness of initial cataract surgery. Ophthalmology 109: 606-612; discussion 612-603. https://doi.org/10.1016/s01616420(01)00971-x

28. Busbee BG, Brown MM, Brown GC, Sharma S (2003) Cost-utility analysis of cataract surgery in the second eye. Ophthalmology 110 : 2310-2317. https://doi.org/10.1016/s0161-6420(03)00796-6

29. Richter GM, Chung J, Azen SP, Varma R (2009) Prevalence of visually significant cataract and factors associated with unmet need for cataract surgery: Los Angeles Latino Eye Study. Ophthalmology 116:2327-2335. https://doi.org/10.1016/j.ophtha. 2009.05.040

30. Nano ME, Nano HD, Mugica JM, Silva JC, Montana G, Limburg H (2006) Rapid assessment of visual impairment due to cataract and cataract surgical services in urban Argentina. Ophthalmic Epidemiol 13:191-197. https://doi.org/10.1080/ 09286580600584699

31. Wadud Z, Kuper H, Polack S, Lindfield R, Akm MR, Choudhury KA, Lindfield T, Limburg H, Foster A (2006) Rapid assessment of avoidable blindness and needs assessment of cataract surgical services in Satkhira District, Bangladesh. Br J Ophthalmol 90:12251229. https://doi.org/10.1136/bjo.2006.101287

32. Ahmad K, Zwi AB, Tarantola DJ, Chaudhry TA (2015) Selfperceived barriers to eye care in a hard-to-reach population: the Karachi Marine Fishing Communities Eye and General Health Survey. Invest Ophthalmol Vis Sci 56:1023-1032. https://doi.org/ 10.1167/iovs. 14-16019

33. Seol BR, Shin JY, Choi S, Kang TG, Jeoung JW, Park KH (2019) Intraocular pressure (IOP) change and frequency of IOP spike after cataract surgery in normal-tension glaucoma: a case-control study. J Glaucoma 28:201-206. https://doi.org/10.1097/ijg. 0000000000001172

34. Azuara-Blanco A, Burr J, Ramsay C, Cooper D, Foster PJ, Friedman DS, Scotland G, Javanbakht M, Cochrane C, Norrie J (2016) Effectiveness of early lens extraction for the treatment of primary angle-closure glaucoma (EAGLE): a randomised controlled trial. Lancet 388:1389-1397. https://doi.org/10.1016/ s0140-6736(16)30956-4

35. Srinivasan S, Raman R, Swaminathan G, Ganesan S, Kulothungan V, Sharma T (2017) Incidence, progression, and risk factors for cataract in type 2 diabetes. Invest Ophthalmol Vis Sci 58:59215929. https://doi.org/10.1167/iovs.17-22264

36. Saxena S, Mitchell P, Rochtchina E (2004) Five-year incidence of cataract in older persons with diabetes and pre-diabetes. Ophthalmic Epidemiol 11:271-277. https://doi.org/10.1080/ 09286580490510733
37. Becker C, Schneider C, Aballea S, Bailey C, Bourne R, Jick S, Meier C (2018) Cataract in patients with diabetes mellitusincidence rates in the UK and risk factors. Eye (Lond) 32:10281035. https://doi.org/10.1038/s41433-017-0003-1

38. Bundesärztekammer (BÄK), Kassenärztliche Bundesvereinigung (KBV), Arbeitsgemeinschaft der Wissenschaftlichen Medizinischen Fachgesellschaften (AWMF) (2015) Nationale VersorgungsLeitlinie Prävention und Therapie von Netzhautkomplikationen bei Diabetes - Langfassung, 2. Auflage. Version 1. [english: national guideline for prevention and therapy of retinal complications in diabetes - long version, $2^{\text {nd }}$ edition, version 1] http://www.netzhautkomplikationen.versorgungsleitlinien. de. Accessed 19.07.2019

39. Tan AG, Kifley A, Tham YC, Shi Y, Chee ML, Sabanayagam C, Tan NYQ, Wong KH, Mitchell P, Cumming RG, Wong TY, Wang JJ, Cheng CY (2018) Six-year incidence of and risk factors for cataract surgery in a multi-ethnic Asian population: the Singapore Epidemiology of Eye Diseases Study. Ophthalmology 125:1844 1853. https://doi.org/10.1016/j.ophtha.2018.07.026

40. Lundstrom M, Stenevi U, Thorburn W (2001) Quality of life after first- and second-eye cataract surgery: five-year data collected by the Swedish National Cataract Register. J Cataract Refract Surg 27: 1553-1559

41. Castells X, Comas M, Alonso J, Espallargues M, Martinez V, Garcia-Arumi J, Castilla M (2006) In a randomized controlled trial, cataract surgery in both eyes increased benefits compared to surgery in one eye only. J Clin Epidemiol 59:201-207. https://doi.org/ 10.1016/j.jclinepi.2005.06.007

42. Elliott DB, Patla AE, Furniss M, Adkin A (2000) Improvements in clinical and functional vision and quality of life after second eye cataract surgery. Optom Vis Sci 77:13-24

43. Hirneiss C (2014) The impact of a better-seeing eye and a worseseeing eye on vision-related quality of life. Clin Ophthalmol 8: 1703-1709. https://doi.org/10.2147/opth.s64200

44. Finger RP, Fenwick E, Hirneiss CW, Hsueh A, Guymer RH, Lamoureux EL, Keeffe JE (2013) Visual impairment as a function of visual acuity in both eyes and its impact on patient reported preferences. PLoS One 8:e81042. https://doi.org/10.1371/journal. pone. 0081042

45. Nickels S, Schuster AK, Elflein H, Wolfram C, Schulz A, Munzel T, Beutel ME, Schmidtmann I, Finger RP, Pfeiffer N (2019) Vision-related quality of life considering both eyes: results from the German population-based Gutenberg Health Study (GHS). Health Qual Life Outcomes 17:98. https://doi.org/10.1186/ s12955-019-1158-1

Publisher's note Springer Nature remains neutral with regard to jurisdictional claims in published maps and institutional affiliations. 